\title{
A rare case of human pulmonary dirofilariasis with nodules mimicking malignancy: approach to diagnosis and treatment
}

\author{
Paolo Albino Ferrari ${ }^{1,5^{*}}$ (D, Antonella Grisolia ${ }^{2}$, Stefano Reale ${ }^{3}$, Rosa Liotta ${ }^{4}$, Alessandra Mularoni ${ }^{2}$
} and Alessandro Bertani ${ }^{1}$

\begin{abstract}
Background: Human pulmonary dirofilariasis is a rare zoonosis caused by the dog worm Dirofilaria spp., a parasite transmitted by mosquitos and resulting in peripheral lung nodules. The filarial nematode enters the subcutaneous tissue, travels to the right ventricle and dies causing a small pulmonary infarction that may embolize through the pulmonary vessels and may appear as a solitary nodule. These nodules are usually incidentally identified in asymptomatic patients undergoing chest imaging studies, and are generally interpreted to be malignant.

Case presentation: We present the case report of a human dirofilariasis in a patient with multiple pulmonary nodules resected using video-assisted thoracic surgery (VATS). According to our literature review, this is the first case with double synchronous lung nodules reported in Italy.

Conclusions: Minimally invasive resection with histologic examination may be the best approach for the diagnosis and treatment of pulmonary dirofilariasis. Polymerase Chain Reaction testing may provide a more accurate etiological diagnosis in case of an inconclusive pathology result.
\end{abstract}

Keywords: Pulmonary dirofilariasis, Video-assisted thoracic surgery, PCR, Lung nodules

\section{Background}

Human dirofilariasis is a zoonotic infection mostly caused by the filarial nematodes Dirofilaria repens and Dirofilaria immitis. It is poorly recognized even in endemic areas such as the Mediterranean and the south of Italy. Dirofilariae are Onchocercidae nematodes that usually target dogs and wild carnivores living in tropical and temperate regions. Humans can be accidentally infected with Dirofilaria larvae through mosquito bites [1, 2]. Nodules presenting in parenchymal organs are often

\footnotetext{
* Correspondence: paoloalb.ferrari@gmail.com; paolo.a.ferrari@aob.it 'Department for the Treatment and Study of Cardiothoracic Diseases and Cardiothoracic Transplantation, IRCCS ISMETT, Via Tricomi 5, Palermo, Italy ${ }^{5}$ Division of Thoracic Surgery, "A. Businco" Oncology Hospital - Azienda Ospedaliera Brotzu, Via Jenner 1, 09100 Cagliari, Italy

Full list of author information is available at the end of the article
}

misidentified as malignant tumors, requiring biopsy or surgery before being correctly diagnosed $[3,4]$.

According to our review of the literature, we report the first case of an Italian patient with two pulmonary nodules, mimicking malignant lesions, which were surgically resected and underwent subsequent morphological and molecular identification of Dirofilaria repens [5-12].

\section{Case presentation}

A 63-year-old woman from the south of Italy was admitted to the thoracic surgical service for the evaluation of two coin lesions of the right lung. The lesions were found incidentally on a chest X-ray (Fig. 1) that the patient received for a clinical suspicion of pneumonia. Past medical and surgical history was unremarkable other 


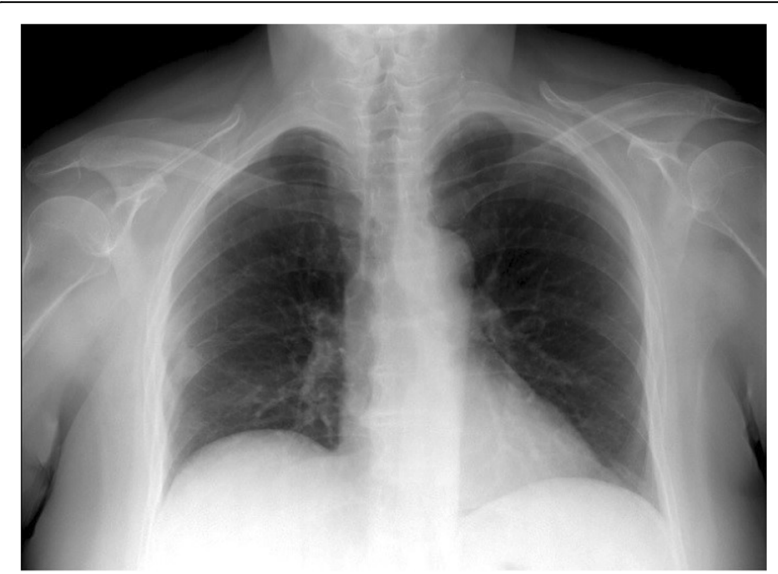

Fig. 1 CXR evidence of peripheral right lung nodules

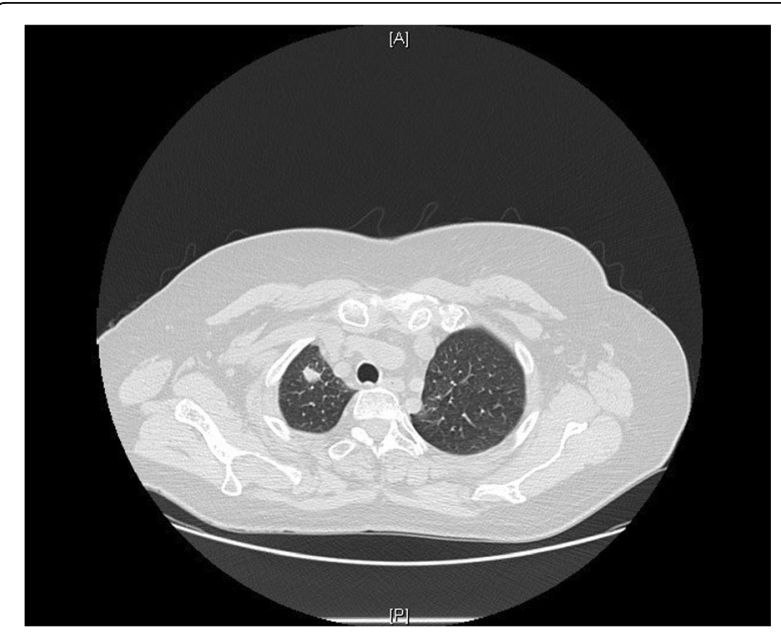

Fig. 2 CT scan showing pulmonary right upper lobe nodule

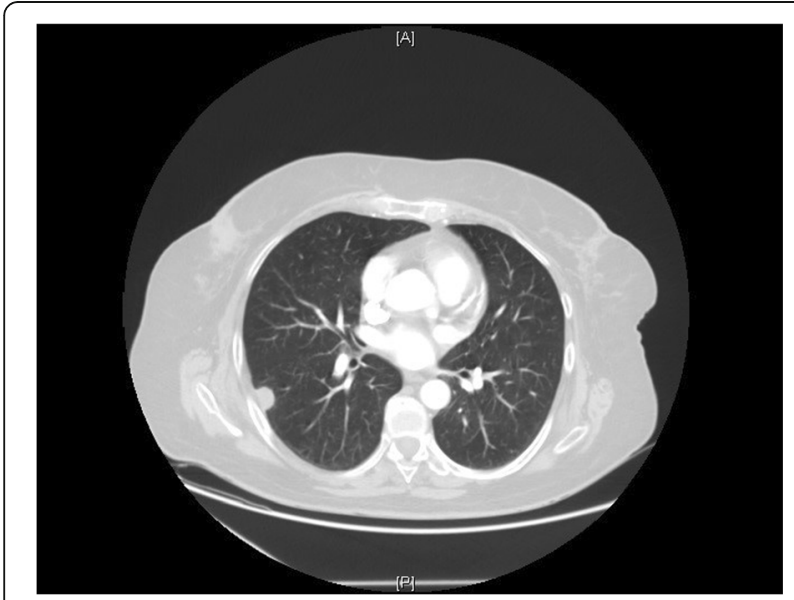

Fig. 3 CT scan showing pulmonary right lower lobe nodule

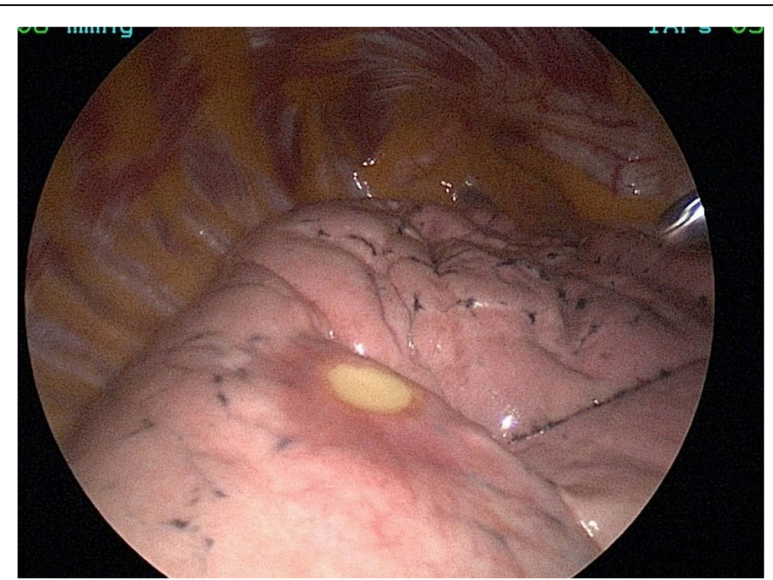

Fig. 4 Thoracoscopic evidence of unusual coin pulmonary lesion

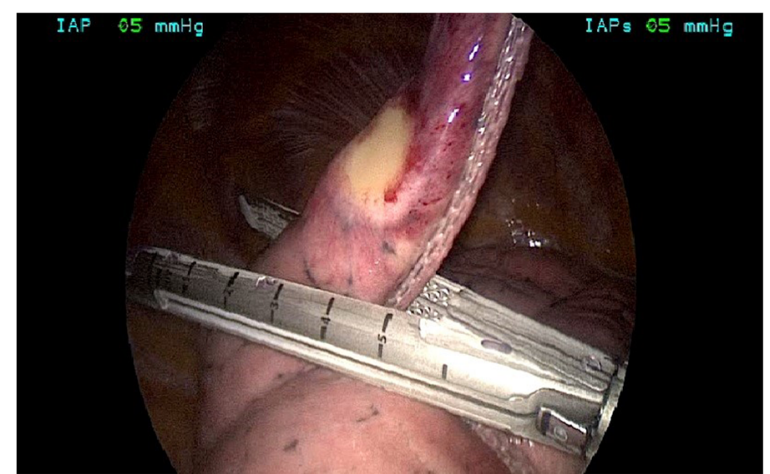

Fig. 5 Thoracoscopic pulmonary wedge resection

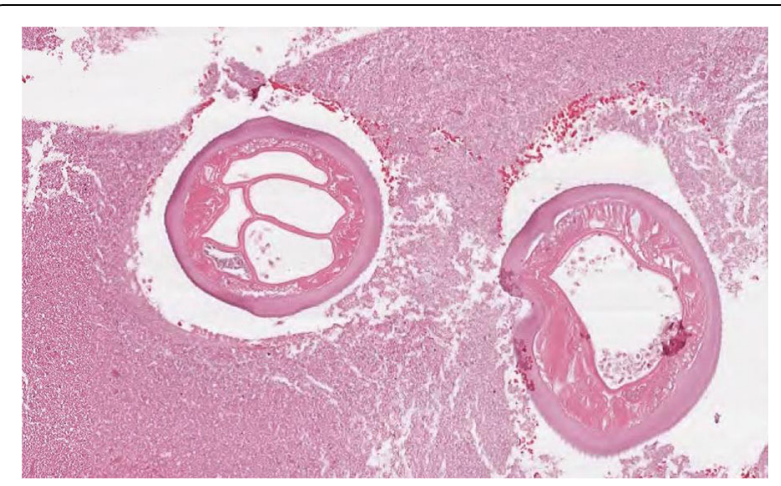

Fig. 6 Cross section of D. repens 
than for cystocele repair at age 36. Further imaging showed two oval-shaped, non-calcified, well demarcated PET-negative lung lesions measuring approximately $13 \times 8 \mathrm{~mm}$ in the apical segment of the right upper lobe and in the superior segment of the right lower lobe (Figs. 2 ,3). Physical examination of the patient and pulmonary function tests were within normal limits $(\mathrm{VC}=108 \%$; FEV1 $=95 \%)$. The white blood cell count was $6520 / \mathrm{ml}$ without eosinophilia (Eosinophils $=1.2 \%$ ). A CT-guided needle biopsy of the lesions was performed, showing CD68+ histiocytes, lymphocytes and myofibroblasts suggestive of a benign, granulation-like tissue. Given the inconclusive diagnosis, two wedge pulmonary resections were performed using a minimal invasive approach (Figs. $4,5)$. The final pathologic review of the resected lesions suggested a morphological diagnosis of human pulmonary dirofilariasis (Figs. 6, 7). Postoperative serological testing for anti-Filaria antibodies using ELISA was consistent with the above diagnosis. The patient had an uneventful recovery and was discharged home on post-operative day 3. A pharmacological treatment was not considered since complete resection is considered to be curative [5].

A biomolecular testing procedure was performed to further validate the diagnosis, and to discriminate the specific Dirofilaria subspecies. Total DNA extraction was carried out from paraffin embedded tissue taken from the lung nodules, by using a QIAmp DNA mini kit. Reference genomic DNA was extracted from animal blood containing D.repens $(15,000 \mathrm{mff} / \mathrm{ml})$. A quantity of 20 ng DNA was used for the amplification with four specific forward primers and a common reverse primer as showed in Table 1. The capillary electrophoresis (Fig. 8) was performed on an ABI Prism 3130 DNA sequencer. The collected data was then analyzed, considering 97\% identity as the stringent parameter for strain identification. Multiplex-PCR cox 1 amplicons from the DNA extracted from the embedded tissue resulted in a band consistent with $D$. repens $(479 \mathrm{bp}$ ). The BLAST analysis of the cox 1 sequences revealed a 99 to $100 \%$ identity compared to the sequences available in GenBank ${ }^{\text {it. }}$.

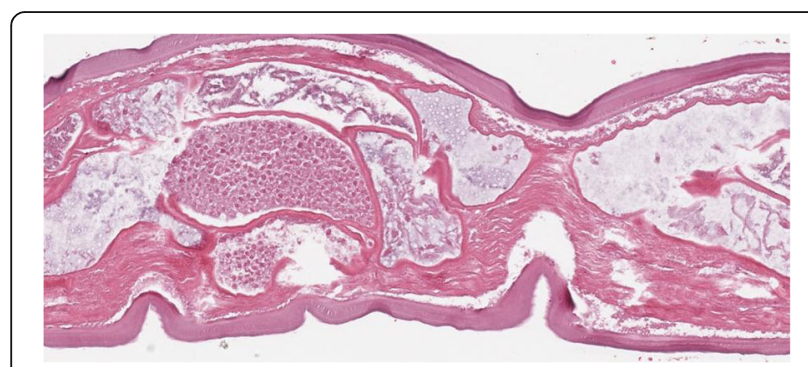

Fig. 7 Longitudinal section of D. repens
Table 1 DNA amplification structure

\begin{tabular}{ll}
\hline PRIMER NAMES & PRIMER SEQUENCES \\
\hline Arcox1F & 5'-ATC TIT GTT TAT GGT GTA TC-3' \\
Cbcox1F & 5'-CGG GTC TTT GTT GTT TTT ATT GC-3' \\
Dicox1F & 5'-ACC GGT GTT TGG GAT TGT TA-3' \\
Drcox1F & 5'-GTA TA TTT TGG GTT TAC ATA CTG TA-3' \\
Common reverse & 5'-ATA AGT ACG AGT ATC AAT ATC-3' \\
primer NTR & \\
\hline
\end{tabular}

\section{Discussion}

Growing concern over D. repens in endemic areas of Southern Europe may be justified by the recent, increasing number of published human cases, with an increasing prevalence in Italy (4.5/year between 1986 and 1998; 15.6/year between 1999 and 2009) [5]. Climate changes, insecticide resistance, expanding geographic distribution of both the vectors and the pathogens via modern transportation and globalization are identified as possible causes of the spreading of vector-borne diseases [3]. Human dirofilariasis is currently considered an emergent zoonosis in Italy [7], France [8], Hungary [9] and Russia [10].

Women have a trend to be more commonly infected than men, although without any statistical difference $[3,6]$. Twenty-seven cases of pulmonary dirofilariasis have been reported in the medical

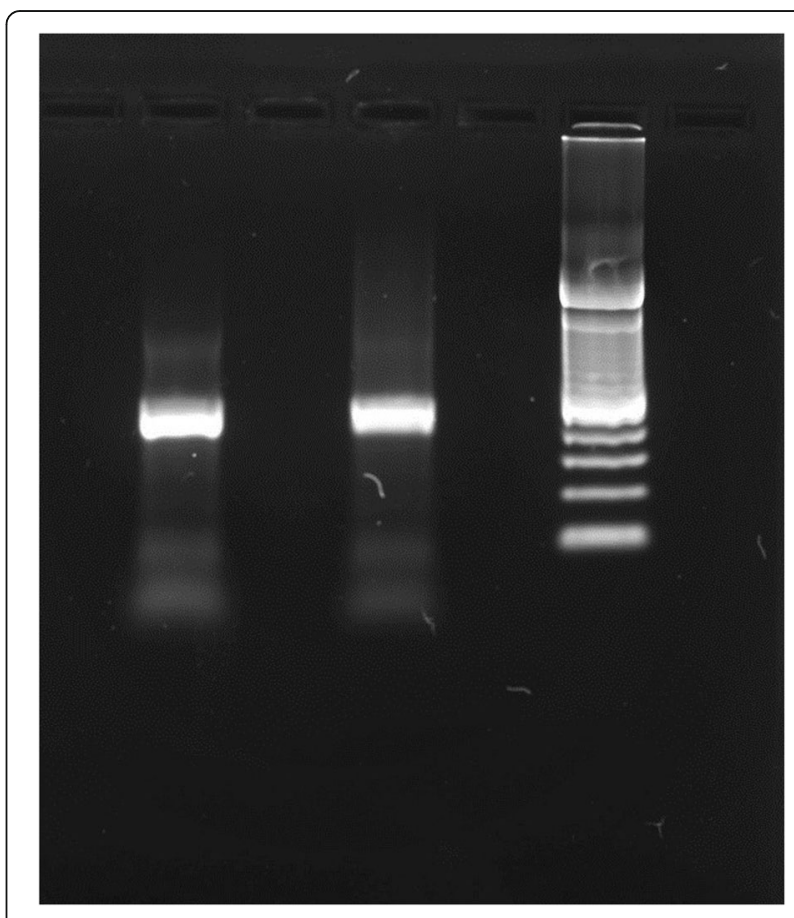

Fig. 8 Electrophoresis on 2\% agarose gel. Lane 1: 480 bp amplicon obtained from human sample. Lane 2: Negative control. Lane 3: 480 bp amplicon obtained from Dirofilaria repens DNA positive control 
literature between 1981 and 2010 [3, 6, 11-13]. The differential diagnosis of the visceral localization of disease frequently (but not only) includes malignancy, requiring a biopsy or surgery for a conclusive histologic diagnosis. More recently, the introduction of molecular methods based on polymerase chain reaction and sequencing has improved diagnostic accuracy [14-17].

The use of minimally invasive techniques for the diagnostic and therapeutic excision of lung nodules of unclear origin should be strongly encouraged. The rarity of this zoonosis may also warrant the use of biomolecular assays as a tool to achieve an unequivocal etiological diagnosis and to assist the histo-pathologic and microbiologic diagnostic interpretation.

\section{Abbreviations}

BLAST: Basic Local Alignment Search Tool; CT: Computed Tomography; CXR: Chest X-ray; ELISA: Enzyme-linked Immunosorbent Assay; FEV1\%: Forced Expiratory Volume \% in the 1st second; PET: Positron Emission Tomography; VC: Vital Capacity

\section{Acknowledgements}

The authors would like to acknowledge all their colleagues at ISMETT and Prof. Laura H. Kramer, from Parma University for her kind contribute to histological diagnosis.

\section{Consent of publication}

The authors declare that they have obtained the consent to publish for this study.

\section{Authors' contributions}

$A B, A M, A G$ and PAF analyzed and interpreted the patient data regarding the clinical and surgical treatments. $A B, A M$ and PAF were the major contributors in reviewing the manuscript. RL and SR performed the histological examination and the molecular analysis of the specimens, respectively. All authors equally contributed to the manuscript writing. They all read and approved the final manuscript.

\section{Ethics approval and consent to participate}

The authors declare that the study has been performed in accordance with the Declaration of Helsinki and it has been approved by the Ethics Committee of ISMETT (CE ISMETT) with number IRRB/09/17.

\section{Competing interests}

The authors declare that they have no competing interests.

\section{Publisher's Note}

Springer Nature remains neutral with regard to jurisdictional claims in published maps and institutional affiliations.

\section{Author details}

${ }^{1}$ Department for the Treatment and Study of Cardiothoracic Diseases and Cardiothoracic Transplantation, IRCCS ISMETT, Via Tricomi 5, Palermo, Italy. ${ }^{2}$ Infectious Diseases Unit, IRCCS ISMETT, Via Tricomi 5, Palermo, Italy. ${ }^{3}$ Istituto Zooprofilattico Sperimentale della Sicilia Adelmo Mirri, Via Gino Marinuzzi 3, Palermo, Italy. ${ }^{4}$ Pathology Service, Department of Diagnostic and Therapeutic Services, IRCCS ISMETT, Via Tricomi 5, Palermo, Italy. ${ }^{5}$ Division of Thoracic Surgery, "A. Businco" Oncology Hospital - Azienda Ospedaliera Brotzu, Via Jenner 1, 09100 Cagliari, Italy.
Received: 27 March 2018 Accepted: 31 May 2018

Published online: 11 June 2018

\section{References}

1. Shibasaki M, Shito I, Konno A, et al. A case of pulmonary dirofilariasis: cytological, pathological and immunological diagnosis. J Jpn Soc Clin Cytol. 1997;36:174-8.

2. Asimacopoulos PJ, Katras A, Christie B. Pulmonary dirofillariasis. The largest single-hospital experience. Chest. 1992;102:851-5.

3. Genchi C, Kramer LH, Rivasi F. Dirofilarial infections in Europe. Vector Borne Zoonotic Dis. 2011:11:1307-17.

4. Fontanelli SL, Gabrielli S, De Angelis M, et al. Dirofilaria repens microfilariae from a human node fine-needle aspirate: a case report. BMC Infect Dis. 2016;16:248

5. Echeverri A, Long RF, Check W, Burnett CM. Pulmonary diroflariasis. Ann Thorac Surg. 1999;67(1):2012

6. Pampiglione S, Rivasi F. Human dirofilariasis due to Dirofilaria (Nochtiella) repens: an update of world literature from 1995 to. Parassitologia. 2000;42: 231-54.

7. Pampiglione S, Rivasi F, Angeli G, Boldorini R, Incensati RM, Pastormerlo M, Pavesi M, Ramponi A. Dirofilariasis due to Dirofilaria repens in Italy, an emergent zoonosis: report of 60 new cases. Histopathology. 2001; 38(4):344-54.

8. Raccurt CP. Dirofilariasis, an emerging and underestimated zoonoses in France. Med Trop. 1999;59(4):389-400

9. Szénási Z, Kovács AHH, Pampiglione S, et al. Human diroflariosis in Hungary: an emerging zoonosis in Central Europe. Wien Klin Wochenschr. 2008:120:96-102.

10. Bronshteĭn AM, Supriaga VG, Stavrovskil Bl, et al. Human dirofilariasis in the Moscow region. Med Parazitol (Mosk). 2003;(4):51-6.

11. Pampiglione S, Canestri Trotti G, Rivasi F. Human dirofilariasis due to Dirofilaria (Nochtiella) repens: a review of world literature. Parassitologia. 1995:37(2-3):149-93.

12. Chazan B, Scherbakov A, Kerner H, Raz R. Autochthonous subcutaneous dirofilariasis in Israel. Harefuah. 2001:140(12):1125-6. 1232

13. Rivasi F, Boldorini R, Criante P, Leutner M, Pampiglione S. Detection of Dirofilaria (Nochtiella) repens DNA by polymerase chain reaction in embedded paraffintissues from two human pulmonary locations. APMIS. 2006;114(7-8):567-74

14. Nuchprayoon S, Junpee A, Poovorawan Y, Scott AL. Detection and differentiation of filarial parasites by universal primers and polymerase chain reaction-restriction fragment length polymorphism analysis. Am J Trop Med Hyg. 2005;73(5):895-900

15. Casiraghi M, Bazzocchi C, Mortarino M, Ottina E, Genchi C. A simple molecular method for discriminating common filarial nematodes of dogs (Canis familiaris). Vet Parasitol. 2006:141(3-4):368-72.

16. Gioia G, Lecová L, Genchi M, et al. Highly sensitive multiplex PCR for simultaneous detection and discrimination of Dirofilaria immitis and Dirofilaria repens in canine peripheral blood. Vet Parasitol. 2010;172(1-2): 160-1633.

17. Latrofa MS, Weigl S, Dantas-Torres F, et al. A multiplex PCR for the simultaneous detection of species of filarioids infesting dogs. Acta Trop. 2012:122(1):150-4.

\section{Ready to submit your research? Choose BMC and benefit from:}

- fast, convenient online submission

- thorough peer review by experienced researchers in your field

- rapid publication on acceptance

- support for research data, including large and complex data types

- gold Open Access which fosters wider collaboration and increased citations

- maximum visibility for your research: over $100 \mathrm{M}$ website views per year

At BMC, research is always in progress.

Learn more biomedcentral.com/submissions 